\title{
THE INFLUENCE OF PALEOCLIMATE ON PRESENT-DAY PATTERNS IN BIODIVERSITY AND ECOSYSTEMS
}

Jens-Christian Svenning ${ }^{1}$, Wolf L. Eiserhardt ${ }^{2}$, Signe Normand ${ }^{1}$, Alejandro Ordonez ${ }^{1} \&$ Brody Sandel ${ }^{1}$

${ }^{1}$ Section for Ecoinformatics \& Biodiversity, Department of Bioscience, Aarhus University, Ny Munkegade 114, DK-8000 Aarhus C, Denmark;

${ }^{2}$ Royal Botanic Gardens, Kew, TW9 3AB Richmond, Surrey, UK

Emails: svenning@bios.au.dk, W.Eiserhardt@kew.org, signe.normand@bios.au.dk, alejandro.ordonez@bios.au.dk, brody.sandel@bios.au.dk

Running title: Paleoclimatic legacies in biodiversity

Corresponding author:

Jens-Christian Svenning

Section for Ecoinformatics \& Biodiversity, Department of Bioscience, Aarhus University

Ny Munkegade 114, DK-8000 Aarhus C, Denmark

Phone: 45+28992304. Email: svenning@ bios.au.dk 

TABLE OF CONTENTS

\section{INTRODUCTION}

\section{PALEOCLIMATE}

\section{PALEOCLIMATIC IMPACTS ON PAST BIODIVERSITY}

Deep-time paleoclimatic changes

Quaternary climate variability

Holocene climate

THEORETICAL PERSPECTIVE ON PALEOCLIMATIC LEGACIES

General

Species distributions and species diversity

Phylogenetic diversity

Functional diversity

Ecosystem functioning

EVIDENCE FOR PALEOCLIMATIC LEGACIES IN DIVERSITY PATTERNS

Species distributions 
Species diversity

Phylogenetic diversity

Functional diversity

Ecosystem functioning

IMPLICATIONS FOR ECOLOGICAL DYNAMICS IN THE ANTHROPOCENE

FUTURE PERSPECTIVES AND EMERGING APPROACHES

ACKNOWLEDGMENTS

LITERATURE CITED 


\section{KEYWORDS}

Climate change, disequilibrium dynamics, dispersal limitation, functional and phylogenetic diversity, history, species distributions and richness 


\begin{abstract}
Climate has experienced strong changes on time scales from decades to millions of years. As biodiversity has evolved under these circumstances, dependence on these climate dynamics is expected. Here, we assess the current state of knowledge on paleoclimatic legacies in biodiversity and ecosystem patterns. Paleoclimate have had strong impacts on past biodiversity dynamics, driving range shifts, extinctions, as well as diversification. We outline theory for how these dynamics may have left legacies in contemporary patterns and review the empirical evidence. We report ample evidence that Quaternary glacial-interglacial climate change affects current patterns in species distributions and diversity across a broad range of organisms and regions, with emerging evidence also for legacies of deeper-time paleoclimate and in patterns in phylogenetic and functional diversity and ecosystem functioning. Finally, we discuss implications for Anthropocene ecology and outline an agenda to improve our understanding of paleoclimate's role in shaping contemporary biodiversity and ecosystems.
\end{abstract}




\section{INTRODUCTION}

Earth's climate has experienced strong changes on time scales from decades to millions of years (Ruddiman 2014). As biodiversity has evolved and diversified under these circumstances, some dependence of biodiversity patterns on these climate dynamics should be expected. While this is increasingly recognized, the role of climate history in shaping the distribution of biodiversity and ecosystems has until recently received limited attention (e.g., Dynesius \& Jansson 2000, Haffer 1969, Ricklefs \& Latham 1999, Wiens \& Donoghue 2004). In the last decade an increasing number of studies have attempted to determine the role of paleoclimate in shaping current diversity patterns, likely to a large extent reflecting three factors, (i) the increasing availability of spatially-explicit paleoclimatic data, (ii) an increasing interest in and ability to test historical and evolutionary hypotheses due to the rapid development in phylogenetics and phylogeography, and (iii) the increasing focus on understanding the importance of climate change for biodiversity and ecosystem functions, driven by the ongoing and forecasted anthropo genic climate change.

Here, we assess the current state of knowledge regarding paleoclimatic legacies in biodiversity patterns. While most of this research has focused on species distributions and species diversity, we will also treat the phylogenetic and functional components of biodiversity. Paleoclimatic legacies in intraspecific genetic diversity have received much attention in phylogeography, but are not covered here. Further, as biodiversity may affect ecosystem functioning (Hooper et al. 2005), we also consider evidence that paleoclimatic effects on biodiversity may penetrate to affect how ecosystems function. Paleoclimate could in principle refer to climate any length of time into the past, but we here restrict ourselves to consider time-scales of

$\geq 10^{2}$ years. We first briefly summarize the main relevant paleoclimatic conditions and changes and their impacts on past biodiversity. We then outline the theory for how paleoclimate might leave 
legacies in contemporary biodiversity and ecosystem patterns and the empirical evidence for such legacies. Lastly, we discuss the implications of legacies for ecological dynamics in the Anthropocene and possible future approaches.

\section{PALEOCLIMATE}

Contemporary species diversity has deep roots, but is mainly the product of diversification within the Cenozoic, i.e., the last 66 million years since the end of Mesozoic era and the demise of nonavian dinosaurs and many other clades. Hence, it is mainly climatic conditions and changes throughout this period that has potential to shape current diversity patterns and three hierarchical aspects might be important: (1) a long-term 107-year scale cooling trend, including Paleogene (6623 mya) and Neogene (23-2.6 mya) climatic and glaciation events, (2) $10^{6}$ - to $10^{5}$-year scale Quaternary glacial-interglacial oscillations, and (3) shorter-term climatic variability, notably within the Holocene (Ruddiman 2014).

The Cenozoic began with a warm greenhouse climate, with unglaciated poles and a flat latitudinal temperature gradient (Ruddiman 2014). Although the exact causes are unclear, cooling and associated drying started at the Eocene/Oligocene boundary 33.8 Mya and culminated with recurring Pleistocene ice ages during the last 2.6 million years (Ruddiman 2014). This cooling is proximally explained by declining atmospheric $\mathrm{CO}_{2}$ concentrations, while the underlying factors are still unclear (Ruddiman 2014): However, plate tectonics are implicated, possibly acting via changes in land mass configurations, sea-floor spreading rates, and orogeny. One of the factors discussed is vertical uplift of large plateaus in the Northern Hemisphere, notably the Tibetan plateau, caused by collision of India into Asia and leading to chemical weathering and draw-down of $\mathrm{CO}_{2}$ as well as changing atmospheric patterns (Ruddiman 2014). The opening of Drake's strait and the isolation of Antarctica is also thought to play a role, triggering the abrupt Eocene-Oligocene cooling and 
extensive Antarctic glaciation (Livermore et al. 2005). Despite the overall cooling trend, there have also been periods with warming during this period (Ruddiman 2014).

The last 2.7 million years have been characterized by repeated large Northern Hemisphere glaciations and a generally cool climate (Ruddiman 2014). The initial trigger is still being discussed, e.g., changes in deep-sea circulation due to growth of the Antarctic ice sheets (Woodard et al. 2014), but it is clear that timing of the subsequent glacial-interglacial cycles is linked to cyclical changes in Earth's orbit, tilt and orientation (Milankovitch cycles) (Ruddiman 2014). While clearly oscillations, each cycle has varied in development and amplitude, with a shift towards longer and deeper glaciations approximately 0.9 million years ago (Ruddiman 2014).

Strong short-term climatic variability has also occurred, notably during glacial periods, e.g., rapid, short cooling periods (Heinrich events) and abrupt, short-lived warming (DansgaardOeschger events) (Ruddiman 2014). During the Holocene, short-term climatic variability has been more muted, but not negligible. There has been millennial-scale and multi-century-scale regional cooling or drying, with the so-called Little Ice Age from 1350-1850 AD as the latest and most wellknown (Mayewski et al. 2004, Wanner et al. 2008).

\section{PALEOCLIMATIC IMPACTS ON PAST BIODIVERSITY}

\section{Deep-time paleoclimatic changes}

The climate changes during the Paleogene and Neogene have elicited marked biotic responses. Warming and cooling events have had strong effects on inter-continental migrations via effects on climatic suitability of dispersal corridors. A short-lived warming event 55.8 mya illustrates this, as it allowed Asian mammal groups to invade North America via a northern corridor, causing large and permanent faunal shifts (Bowen et al. 2002). There are also many examples of climate-driven 
range shifts within continents, such as drying-linked range contractions among African palms during the last 30 million years (Pan et al. 2006) and orbitally-driven range oscillations in tree taxa in Europe during the Pliocene (Willis et al. 1999). There are also many examples of strong regional climate-driven extinctions during the Paleo- and Neogene (e.g., Lewis et al. 2008). Some clades such as gymnosperms have been strongly affected globally by climate-linked extinctions during this time frame (Crisp \& Cook 2011). At the same time, there is also evidence for phylo- and anagenetic responses to these deep-time climate changes, e.g., radiations in drought-adapted plants during Neogene drying in Australia (Crisp et al. 2004).

\section{Quaternary climate variability}

The Quaternary glacial-interglacial climate oscillations have caused strong biodiversity responses. The strong climate changes caused large range shifts in many species (Huntley \& Webb III 1989), and in some areas numerous species contracted into refugia during glacials (Carnaval et al. 2009, Hewitt 2000). These dynamics affected some regions more strongly than others (Rodríguez 2006).

The repeated retractions to refugia and associated population fragmentation have been hypothesized to promote allopatric speciation in Amazonia and other regions (Haffer 1969). While this hypothesis has largely been falsified for Amazonia (Hoorn et al. 2010), the mechanism has found some support in other regions (e.g., Maldonado-Coelho 2012). Additionally, there is evidence of diversification of some groups into the increasingly available cold and dry habitats (e.g., Paun et al. 2005). In terms of anagenesis, there are many cases where the climate conditions of the Quaternary have driven evolutionary adaptation, e.g., in mammals, where both evolution of adaptations to specific habitats and generalist adaptations enabling broad niches and survival of major environmental changes are seen (e.g., Lister 2004). 
Quaternary glacial-interglacial climate oscillations have caused regional and global extinctions. Severe regional extinctions affecting a wide range of organisms occurred in response to the initial glacial cycle, e.g., trees in Europe (Svenning 2003, Willis et al. 1999) and Australia (MacPhail et al. 1995) and molluscs in the North Sea and the Mediterranean (Raffi et al. 1985) and California (Bowersox 2005). Climate-related extinctions continued through the later glacialinterglacial cycles, but generally at a much lower rate (Postigo Mijarra et al. 2010, Raffi et al. 1985), likely because ecologically and geographically sensitive taxa had already been filtered away (Raffi et al. 1985). A major bout of extinctions appears to be associated with the shift to highamplitude, long glacial-interglacial cycles in the Middle Pleistocene (Azzaroli et al. 1988, Postigo Mijarra et al. 2010). During the last glacial-interglacial cycle only a few species were lost due to climate changes, e.g., the ulmaceous tree Zelkova from the European mainland going into the Last Glacial Maximum (LGM, 21,000 years ago) (Follieri et al. 1986) and the North American spruce Picea critchfieldii during the late-glacial warming (Jackson \& Weng 1999). One exception is the massive global loss of large animals during the Late Pleistocene and early Holocene - however, increasing evidence points to Homo sapiens as the culprit behind these extinctions (Sandom et al. 2014).

\section{Holocene climate}

The Holocene is too short to have allowed speciation in most cases (Lister 2004). The relatively subdued climatic variations appear not to have caused global extinctions (ignoring some doubtful cases), but have driven regional range dynamics. For example, a number of species retracted towards the poles during the initial warming (e.g., Sommer et al. 2014), with similar responses to later warmings (Terry et al. 2011). Numerous other responses to temperature changes have also been reported, e.g., marked changes in animal and plant communities in response to the cooling of 
the Little Ice Age (Campbell \& McAndrews 1993, Hu et al. 2013). Strong range responses to precipitation changes are also seen, especially in ecotonal areas (e.g., Watrin et al. 2008).

In summary, past climate conditions have affected speciation, extinction and migration and led to biodiversity changes. Some of these changes might have vanished with the passage of time, while others might have left lasting imprints in current patterns of species distributions, multiple facets of diversity, and even ecosystem functioning. In the following, we first outline the theory for how paleoclimate might leave legacies in contemporary biodiversity patterns, and then turn to the empirical evidence for such legacies.

\section{THEORETICAL PERSPECTIVE ON PALEOCLIMATIC LEGACIES}

\section{General}

We define historical legacies as phenomena where current patterns are influenced by past conditions. Following (Ricklefs \& Latham 1999) we recognize two kinds of historical legacies. The first is a lasting effect of transient past events such as glaciations and climatic excursions. The second is a cumulative effect of time-dependent ongoing processes, such as the diversification of clades over time. Several types of dynamics may lead to such legacies. Historical factors should act differently on ecological state variables that are near their ecological equilibrium compared to those that are far from an equilibrium or have no equilibrium on the time-scales of interest (Figure 1). Among state variables close to an equilibrium (Figure 1AC), a transient event that perturbs the system away from the equilibrium or a shift to a new equilibrium can produce time lags. A time lag describes the amount of time that elapses before the state returns to an equilibrium, and the dynamics experienced during that period are called transient dynamics (Hastings 2004). Time lags occur frequently in biogeography and ecology (e.g., Svenning \& Sandel 2013). If time lags are large 
relative to the frequency of changes in equilibrium states, then disequilibrium dynamics are likely to be a ubiquitous feature (Hastings 2004, Svenning \& Sandel 2013). On the other hand, some ecological state variables are likely to be far from equilibrium and driven primarily by intrinsic dynamics (Figure 1BD). In such circumstances, even a short-lived perturbation can have a permanent legacy.

\section{Species distributions and species diversity}

There are a number of important mechanisms by which time lags may influence species distribution and richness patterns, with different characteristic time scales (Figure 2). Over relatively short periods, lags in population dynamics can be important. Competing tree species in forest simulation models can coexist for $>1000$ years, despite their equilibrium densities being zero (Pacala et al. 1996), and a similar mechanism underlies the coexistence of species in neutral theory (Hubbell 2001). The important implication is that diversity can be shaped by extremely rare historical disturbance events or gradual changes in climatic conditions. An important class of time lags refers to slow responses of species ranges to glacial-interglacial climate cycles. Proposed by Dynesius and Jansson (2000), these dynamics are referred to as orbitally-forced species' range dynamics (ORD). The species composition in areas with strong ORD should be heavily influenced by dispersal lags. Considerable time might pass between when conditions become suitable for a species, and when it actually arrives. Because this lag is expected to depend on dispersal ability, communities exposed to high ORD are likely to contain particularly many vagile species (Dynesius \& Jansson 2000, Jansson \& Dynesius 2002). There could also be time lags in response to deeper-time climate changes, but these have not received much attention.

The number of species in a region is the sum of all species occurring there. There is much evidence suggesting that assemblages are often not saturated (Morlon et al. 2010, Stohlgren et al. 
2008, Szava-Kovats et al. 2013), opening the door for historical effects. Hence, time-lagged migration and extinction effects on species ranges as discussed above will directly affect species richness. Paleoclimate conditions may also influence current diversity patterns via regional species pool effects. These effects may occur when one set of conditions predominated in the past. Following the appearance of a novel climate, species richness there could initially be low, because relatively few species in the pool can survive there. Some time lag should occur before species richness in the novel condition reaches in equilibrium, via in situ diversification and adaptation. This mechanism is at the heart of the tropical niche conservatism hypothesis (Wiens \& Donoghue 2004), but has also been applied to explain e.g., species richness-soil relations (e.g., Ewald 2003, Laliberté et al. 2014). If clades have speciation and extinction rates that are dependent on climate, but largely independent of their species richness, richness is likely to be particularly strongly impacted by paleoclimate, since its influence on species richness may persist indefinitely (Figure 1B). A recent analysis of a large number of phylogenies from a broad range of organisms found that most clades have not reached their diversity limit, but are experiencing slowdowns in speciation rates (Morlon et al. 2010).

\section{Phylogenetic diversity}

Phylogenetic diversity describes the collective evolutionary distinctiveness of a set of species and may depend on past climate via the same mechanisms as species richness (Figure 3), e.g., niche conservatism may generate phylogenetic clustering in novel climates (Hawkins et al. 2014, Miller et al. 2013). In addition, phylogenetically distinct species, and thus high phylogenetic diversity, occur in lineages with low speciation rates or high extinction rates, which may depend mechanistically on climate (Figure 3A). This hypothesis has received considerable attention in the context of the latitudinal gradient of diversity, postulating higher speciation and/or lower extinction in high-energy 
climates (Mittelbach et al. 2007). ORD have been proposed to either increase diversification by inducing allopatric speciation (Haffer 1969), or decrease diversification by preventing the formation of stable isolate populations that can develop into separate species (Dynesius \& Jansson 2000, Jansson \& Dynesius 2002). Strong climatic fluctuations or short periods of extreme climate may shape phylogenetic diversity by selective extinction (Eiserhardt et al. 2015) or recolonization (Hortal et al. 2011). This mechanism would generally lead to low phylogenetic diversity if extinction vulnerability or dispersal capacity show phylogenetic signal (Figure 3B).

\section{Functional diversity}

Functional diversity describes the value and range of functional traits within an assemblage. Functional traits can be defined as attributes that determine sensitivity to the environment (response traits) or environmental impacts (effect traits) (Lavorel \& Garnier 2002). Much work has been done on determining broad-scale variation in functional diversity, finding strong associations to current climate (e.g., Wright et al. 2005). While not much studied, there is also evidence that functional diversity can be strongly shaped by historical factors, e.g., idiosyncratic lineage evolution and regional diversification (Couvreur et al. 2015). Therefore, it is also conceivable that functional diversity may be influenced by similar disequilibrium dynamics as described for species diversity.

These effects could involve both evolutionary lags and filtering processes (Figure 4). The matching of response traits to a given climate depends on evolutionary trait development and/or immigration of species with climatically matching traits (Ackerly 2003), processes that may exhibit lags in response to climatic changes. Exemplifying such lags, African proboscideans only achieved maximal values of lamellar number and hypsodonty at least 7 Myr after the onset of a grazingdominated diet, in response to Cenozoic drying (Lister 2013). Given the role of traits in determining vagility, dispersal-related traits may lead to paleoclimatic legacies in functional diversity via time- 
lagged dispersal or indirectly via interdependencies with other traits Climatically-driven extinctions may affect functional diversity if they filter according to climatic tolerances (Svenning 2003) and directly or indirectly associated traits (Figure 4). Climatic instability such as high ORD is expected to select for traits associated with generalism and vagility, enhancing the ability to survive in situ and to track shifting habitats (Dynesius \& Jansson 2000, Jansson \& Dynesius 2002).

\section{Ecosystem functioning}

Ecosystem functioning encompasses the level, rate and dynamics of ecosystem properties such as biomass, productivity, and nutrient cycling and is often linked to species and functional diversity (e.g., Flynn et al. 2011). Legacies in the species and functional trait pool due to transient climatic changes (removal of species and functional states) or cumulative effects (accumulation of species and functional states over time) could also affect ecosystem functioning, notably via interdependencies between response and effect traits (Figure 5). Although not climate linked, studies that indicate that ecosystem functioning is affected by long-term historical legacies mediated by species pool effects on functional diversity illustrate the scope for similar paleoclimatic historical effects. One remarkable example concerns the stature of tropical forests. The historical restriction of the tall-growing tree clade Dipterocarpoideae to southeast Asia and neighboring areas offers a likely explanation for the much greater average height, productivity and biomass of this region's forests compared to those in South America after controlling for soil and climate (e.g., Banin et al. 2014). Many examples from human-induced biological invasions also show that there are historical constraints on the distribution of functional groups across the World, with important impacts on ecosystem functioning, e.g., Eurasian earthworm invasions in North America (Frelich et al. 2006) and invasions of Northern Hemisphere pines (Pinus) across the Southern Hemisphere (Richardson et al. 1994). 


\section{EVIDENCE FOR PALEOCLIMATIC LEGACIES IN DIVERSITY PATTERNS}

In this section, we synthesize the evidence for imprints of paleoclimate on current patterns of species distributions, species richness, and phylogenetic diversity, and also cover the emerging interest in their effects on functional diversity and ecosystem functioning.

\section{Species distributions}

The geographic distributions of all species are limited in space and the limits have long been attributed to unsuitable climate or geographic barriers. While there is no doubt that these are major determinants of species ranges at large spatial scales, there is increasing evidence that paleoclimate also plays a role.

Paleoclimatic changes during the Paleo- and Neogene have enabled or hindered exchange of species among regions as well as driven regional extirpations, thereby leaving marks in the distribution of species and genera. Among temperate plants, a few species and many genera are disjunct between eastern North America and East Asia, reflecting past connectivity across the Bering land bridge as well as climate-driven extirpations from Europe and western North America (Donoghue \& Smith 2004). Many others are now restricted to East Asia, following similar extinction dynamics (Manchester et al. 2009). Similar dynamics also shape distributions elsewhere, e.g., in the Southern Hemisphere (e.g., Hill 2004, Wilf et al. 2003).

Much empirical evidence shows that Quaternary glacial-interglacial oscillations have left legacies in current species ranges. It has long been debated to which degree time-lagged dispersal responses have left imprints of past climate change in the present-day geographic ranges (e.g., Davis 1986, Prentice et al. 1991). Hutchinson (1918) argued that if tree species migration has kept pace with the postglacial temperature changes, then climatic isoclines and distributional limits 
should coincide, but found this to not be the case for some North American tree species (Tsuga canadensis, Acer saccharum, and Fagus americana), concluding that in many places the migration of these species has lagged behind the temperature changes. A similar conclusion was reached by recent detailed studies of other North American and European tree species, e.g., Pinus contorta (Johnstone \& Chapin 2003), Picea glauca (Caccianiga \& Payette 2006), Fagus sylvatica (Saltré et al. 2013), and Quercus cerris (Nobis \& Normand 2014). Further evidence comes from an increasing number of broad-scale studies of large sets of European plant species, finding that many species have low range filling (Dullinger et al. 2012b, Svenning \& Skov 2004) and are still somewhat restricted by accessibility to recolonization from glacial refugia (Normand et al. 2011, Svenning et al. 2008b, Willner et al. 2009). In northwestern North America, mesic-adapted plants exhibit much lower range filling in a formerly largely glaciated region relative to a region less impacted by glaciation (Gavin 2009). Legacies between $10^{3}-10^{4}$ years are thus a common result of the Quaternary glaciations. Several studies provide evidence for a link between low vagility and low range filling (Dullinger et al. 2012b, Gavin 2009, Normand et al. 2011). Other mechanisms contributing to these migration lags could be several distance refuge locations (Nogués-Bravo et al. 2014) and interspecific constraints on migration rates (e.g., competition for light or lack of mutualistic interactions) (Svenning et al. 2014).

Time-lagged local extinction may also leave imprints of past climatic changes, as remnant populations may persist despite climate conditions that cannot sustain a viable population over the long term (Eriksson 1996). Studies of tree rings in individuals of one of the world's longest living species, the spectacular bristlecone pines (Pinus longaeva) in western North America, have shown that during several hundred years of unfavorable conditions no new trees established, but some adult trees survived, leaving the initial tree-line unaffected (LaMarche 1973). Another example is small-leaved lime (Tilia cordata) in northern Europe, where the species established during warmer 
climates, but now fail to reproduce, persisting clonally (Pigott 1991). A 13,000 years age for a relict clone of Quercus palmeri illustrates that such extinction lags may also last up to $10^{3}-10^{4}$ years (May et al. 2009), although they may often be shorter, especially where dependent on the longevity of single individuals.

\section{Species diversity}

There is increasing evidence for imprints of paleoclimate on current patterns of species diversity, supplementing links to the contemporary environment such as current climate and topography. We note that the latter relations to modern environment may themselves also include a paleoclimatic signal since geographic and topographic climate configurations themselves have long histories (cf. Ruddiman 2014), as discussed in several studies (Lobo et al. 2001, Svenning et al. 2008a, Svenning \& Skov 2007, Wiens \& Donoghue 2004). Hence, a broad-scale relation between species richness and a contemporary gradient in climate may in fact reflect the cumulative response of diversification to the persistence of such a gradient across millions of years (e.g., Svenning et al. 2008a, Wiens \& Donoghue 2004).

A few studies have looked for - and found - evidence that species diversity may also be shaped by pre-Quaternary climatic changes (Blach-Overgaard et al. 2013, Couvreur et al. 2015, Fine \& Ree 2006, Jetz \& Fine 2012, Kissling et al. 2012a, Ricklefs \& Latham 1999). Notably, biome-scale tree species richness exhibits stronger correlations to Paleo- and Neogene climaticallycontrolled biome area than to current biome area (Fine \& Ree 2006), with similar results also reported for vertebrate species richness (Jetz \& Fine 2012). More indirectly, other studies report strong differences in species richness among biogeographic regions that are consistent with Paleoand Neogene climate alone (Kissling et al. 2012a) or jointly with Quaternary changes (Ricklefs \& Latham 1999). Illustrating that within-region patterns may also be linked to deep-time climate, a 
study of African palms found that accounting for present-day environment, rain-forest palms exhibit greater species richness where Pliocene precipitation was relatively high, whereas open-habitat palms are more species-rich in areas that were relatively dry during the Miocene (Blach-Overgaard et al. 2013). Hence, there is emerging evidence for deep-time paleoclimatic legacies in current species diversity patterns, but more work is needed to assess their general importance.

In contrast, many studies show that Quaternary climatic change can still be evident in current patterns of species richness and endemism. On a global scale, high endemism in both plants and animals is associated with low glacial-interglacial climatic variability (Jansson 2003, Sandel et al. 2011, Tedesco et al. 2012). Several studies document the importance of climate stability and accessibility to past refugia for the current richness patterns of plants (especially narrow-ranged) in Europe (Svenning et al. 2010, Svenning \& Skov 2007, Willner et al. 2009) and western North America (Gavin 2009) and of reptiles, amphibians, and small-range mammals in Europe (Araújo et al. 2008, Fløjgaard et al. 2010). A study of 19 beetle clades found that the more poorly dispersed groups exhibit steeper latitudinal gradients in richness in Europe, consistent with postglacial immigration lags (Baselga et al. 2012b). In the Arctic, time-lagged postglacial immigration has led to reduced plant species richness on many islands (Hoffmann 2012). The legacies of the Quaternary climate fluctuations are also pronounced in tropical regions. Late Quaternary stability of rain forest is a dominant determinant of richness patterns for small-ranged and low-dispersed animals in tropical Australia (Graham et al. 2006) and for plant and animal endemism patterns in Atlantic Brazil (Carnaval and Moritz 2008). Similarly, Madagascar's mostly small-ranged palm species are more species-rich where glacial precipitation was conducive to rainforest persistence (Rakotoarinivo et al. 2013). Quaternary coral reef habitat stability and accessibility to recolonization from such stable reef areas is also the main positive drivers of coral reef fish species richness (Pellissier et al. 2014). In summary, many studies document Quaternary climatic variability 
as an important co-determinant of species richness for various groups of organisms across all latitudes, in particular for small ranged or poorly-dispersed species.

A number of studies have assessed the existence of paleoclimatic legacies in another aspect of species diversity, namely spatial species turnover (beta diversity s.l.), all focusing on Quaternary glacial-interglacial climatic variability. Quaternary climate change plays a major role in shaping global patterns of spatial turnover in several vertebrate groups (Baselga et al. 2012a, Dobrovolski et al. 2012, Leprieur et al. 2011) and possibly also in vascular plants (Fitzpatrick et al. 2013). Baselga et al. (2012a) suggest that patterns in amphibian beta diversity are driven by speciation and persistance in paleoclimatically stable areas, while species losses determine patterns in unstable areas. Further, Quaternary glaciation effects are stronger for more poorly dispersed groups (Dobrovolski et al. 2012). The importance of Quaternary-scale climate stability has also been documented at regional scales. In tropical Australia species turnover in low-dispersed, narrowranged groups of rainforest animals is largely determined by paleoclimatically determined habitat connectivity, while current environmental variation determine species turnover in well-dispersed groups (Graham et al. 2006). There are similar cases for other organism groups and regions, e.g., earthworms and long-horn beetles in Europe (Baselga 2008, Mathieu \& Davies 2014) and vascular plants in North America (Qian \& Ricklefs 2007). Importantly, a comparison of two mountain regions in Europe found greater spatial turnover in arctic-alpine plants at not just regional, but also down to local scales in the region less affected by Pleistocene glaciations (Lenoir et al. 2010), indicating that large-scale paleoclimatic legacies may also affect local community patterns and assembly processes.

\section{Phylogenetic diversity}


There is evidence for legacies of both deep-time $\left(10^{7} \mathrm{yr}\right)$ and Quaternary $\left(10^{5}-10^{6} \mathrm{yr}\right)$ climate change in phylogenetic diversity patterns. Effects of Holocene climate change are conceivable, but have not been documented, except for very recent climate change (Willis et al. 2008).

On multimillion year time scales, climatic effects on speciation and extinction may cumulatively influence present-day phylogenetic diversity (Figure 3A), but the evidence for such an effect is mixed. While some studies found an effect of climate on diversification rates (Rolland et al. 2014), others have not (Soria-Carrasco \& Castresana 2012). Correlations between phylogenetic diversity and current climate have also been attributed to paleoclimatic effects on speciation and extinction (e.g., Feng et al. 2015, Svenning et al. 2008a). In palms, phylogenetic diversity is strongly related to climatically-controlled cumulative area of the rainforest biome during the Cenozoic (Kissling et al. 2012b), indicating that paleoclimate might influence phylogenetic diversity via time-integrated area effects on speciation and extinction (Fine \& Ree 2006).

There is some empirical evidence for Quaternary climate change effects. There is evidence that Pleistocene glaciations - to some extent jointly with Neogene cooling - induced phylogenetically selective extinction among temperate trees, resulting in floras with reduced phylogenetic diversity in regions with strong climate-driven extinction (Eiserhardt et al. 2015). Likewise, phylogenetic diversity patterns in Chinese forest trees was best explained by paleoclimate change, with increasing phylogenetic clustering in plots with the strongest climate change since the LGM (Feng et al. 2014). A global study on mammals also suggests that LGM climate acted as an extinction filter, shaping their phylogenetic endemism (a range-size weighted measure of phylogenetic diversity) (Rosauer \& Jetz 2015). Finally, climate-driven extinctions may cause patterns in phylogenetic diversity even if they remove species indiscriminately, if there is phylogenetic pattern in the ability of species to recolonize areas subsequent to extinction episodes. 
For example, northern Europe was recolonized by closely related dung beetles, leading to a northsouth gradient in phylogenetic assemblage structure (Hortal et al. 2011). A study on tropical Australian plant communities found an association of high PD with areas that were deforested during glacial periods, presumably because those communities have been more easily invaded by distantly related lineages from an adjacent biogeographic region (Costion et al. 2015). Due to those multiple effects that are presumably partly lineage- and region-specific, the general relationship between past climate change and phylogenetic diversity needs further investigation.

\section{Functional diversity}

Few studies have assessed the existence of paleoclimatic legacies in functional diversity. Notably, very little attention has been paid to potential deep-time legacies. One example concerns the woody dicot leaf margin-temperature relation in temperate South America, which deviates from its Northern Hemisphere counterpart, likely as a legacy of warmer Paleogene climates (Hinojosa et al. 2011). Another example concerns the underrepresentation of small fruit sizes among African palms relative to other regions, which may represent extinction filtering by pre-Quaternary drying (Kissling et al. 2012b).

A number of studies suggest that Quaternary glacial-interglacial climate variability has imposed historical legacies in functional diversity in plant and animal assemblages in Europe via postglacial migrational lags. Species that fill more of their potential range tend to be relatively coldtolerant, likely reflecting effective postglacial recolonization from high-latitude glacial refugia (Bhagwat \& Willis 2008, Nogués-Bravo et al. 2014, Svenning \& Skov 2004), and have traits associated with higher vagility (Dullinger et al. 2012b, Nogués-Bravo et al. 2014, Normand et al. 2011). Analogously, among European beetle clades those with poorer dispersal ability exhibit the steepest latitudinal declines in species richness (Baselga et al. 2012b). Outside Europe, among 
mesic-adapted plants in the Pacific Northwest species with animal-dispersed seeds occupy a larger portion of formerly glaciated areas than species with less dispersal potential (Gavin 2009). Hence, traits in assemblages far from glacial refuge locations should be more aggregated, as warmthdemanding and poorly dispersed species are disproportionally missing. Along these lines, among European earthworm assemblages, the less mobile large-bodied species are concentrated in the more stable regions, where functional dispersion is also higher (Mathieu \& Davies 2014). In contrast, there were no glacial legacies in tree functional diversity patterns across Chinese forests (Feng et al. 2014).

While there is clear potential for paleoclimatic legacies in functional diversity patterns and some supporting empirical evidence, the latter is too limited to generalize their importance relative to the well-documented links to contemporary environment (e.g., Wright et al. 2005).

\section{Ecosystem functioning}

Not much empirical work has been done on paleoclimatic legacies in ecosystem structure and processes, so our knowledge in this area is limited. Climate stability is expected to influence species coevolution, with tight species partnerships being less likely in unstable climates, with potential consequences for the functioning of such networks and the ecosystems they are embedded in. Several studies have tested this idea, in the context of effects of glacial-interglacial climate stability on plant-pollinator and plant-frugivore networks, with somewhat mixed results (Dalsgaard et al. 2011, Schleuning et al. 2012, Dalsgaard et al. 2013, Schleuning et al. 2014). Hence, more work is needed to elucidate the generality of such stability effects on ecological networks. Most other cases so far published concern relatively short-term $\left(10^{2}-10^{4}\right.$ year) disequilibria, especially for ecosystem structure. Notably, there is evidence for such lags in shifts from tundra to forest in response to short climatic fluctuations during the last glacial (Huntley et al. 2013), for some tree lines in responses to 
postglacial warming, especially where topographic barriers have delayed migration (Payette 2007), as well as from studies simulating responses to future warming (Chapin \& Starfield 1997, Normand et al. 2013). There are also indications that even longer lags can occur, e.g., where immigration of key growth forms such as trees are strongly delayed by severe barriers. An illustrative case comes from the last interglacial in Greenland where the effectively dispersed, tall-growing temperate fern Osmunda became dominant under boreal climate conditions for several thousands of years, likely due to the failure of boreal trees to immigrate from the nearby continents during this period (de Vernal \& Hillaire-Marcel 2008). Potentially reflecting $10^{4}$-year postglacial scale lags, a study documenting dispersal limitation of the northwards expansion of pine into northwestern American boreal spruce-dominated forests highlights the likely strong consequences for ecosystem processes such as fire regime, forest productivity, and carbon storage (Johnstone \& Chapin 2003).

\section{IMPLICATIONS FOR ECOLOGICAL DYNAMICS IN THE ANTHROPOCENE}

The existence of paleoclimatic legacies suggests that anthropogenic climate change is likely to also induce long-term legacies. Of the two types of historical legacies, these will generally fall into the category of lasting effect of transient past events, given that anthropogenic climate change is likely to have a transient effect on Earth's climate, albeit potentially lasting for $10^{4}$ to $10^{5}$ years (Herrero et al. 2014). These legacies likely include both climate-driven directional changes towards equilibrium conditions on $10^{5}$-year time scales or shorter (Svenning \& Sandel 2013) as well as quasi-chronic changes due to reshaping of regional species pools via extinction and long-distance dispersal. Concerning the former, modelling studies suggest that we should expect disequilibria not just in assemblage composition (Dullinger et al. 2012a, Normand et al. 2013), but also in ecosystem structure, with tree-line advances lagging behind climate for $10^{2}-10^{3}$ years (Chapin \& Starfield 1997, Normand et al. 2013). Climate-induced extinctions in regional species pools may have even 
longer lasting effects (cf. Eiserhardt et al. 2015). Still, it is unclear how strong such losses generally will be (Thuiller et al. 2011) and how much they will affect functional diversity (Thuiller et al. 2014). Climatic breakdown of biogeographic barriers, e.g., allowing migration between the Pacific and the Atlantic, could also have strong and long-lasting consequences (Wisz et al. 2015), as seen prehistorically (Bowen et al. 2002).

The existence of paleoclimatic legacies also has important implications for conservation actions. They indicate that species are often not able to track climate changes and point to the need for considering assisted migration as a tool to preserve biodiversity and sustain or restore ecosystem functioning under future climate change (Lunt et al. 2013). This will particularly be the case for the broader landscape and in particular in human-impacted and/or lowland areas where it will be most difficult for species to migrate fast enough to track climate change, as already seen now (Bertrand et al. 2011). At the same time, as active relocation will be unfeasible for much of biodiversity, there will be a strong need for focusing protecting areas that offer good local possibilities for climate tracking or will act as climatically stable refugia (Ackerly et al. 2010, Loarie et al. 2009).

\section{FUTURE PERSPECTIVES AND EMERGING APPROACHES}

Both theory and empirical evidence point to the likely importance of paleoclimatic legacies for both biodiversity and ecosystems. However, there is a clear need to develop theory and analytical approaches and to broaden the empirical basis. One focal point for future research should concern historical legacies in functional aspects of ecosystems. As discussed above, there are reasons to think that such legacies could be widespread and important. However, the theoretical basis is poorly developed and empirical studies are scarce. 
There is a strong necessity for developing a systematic analytical framework for assessing the importance of paleoclimate in shaping contemporary biodiversity and ecosystems, i.e., jointly with other potential determinants. Importantly, the majority of studies of biodiversity and ecosystem patterns still do not consider the potential role of paleoclimate in co-determining the observed patterns, despite their potential importance in many cases. Further, the relatively few studies directly representing paleoclimate are often shaped by data availability and use disparate analytical frameworks and methods, limiting their comparability. Inferring paleoclimatic legacies is challenging because data spanning multiple timescales need to be integrated, and there is a clear need for better integration of current ecological data and the paleo-record (Fritz et al. 2013). Stronger tests will be possible by analyzing trajectories of change through time. Methods for including global climate dynamics are becoming available (Condamine et al. 2013), but ideally climate trends should be included at high temporal and spatial resolution.

Identifying deep-time paleoclimatic legacies offer particular challenges. This is due to difficulties with i) reconstructing the timing of past speciation and extinction events, ii) reconstructing the climatic conditions under which they happened, and iii) inferring if the descendants of those events have retained their geographic distributions and climatic associations to a degree that is sufficient to affect present-day biodiversity patterns. Developing macroevolutionary models that integrate those aspects in a single framework is an important future challenge (Lawing \& Matzke 2014), as is the integration of neo- and paleoecological data sources to parameterize such models (Fritz et al. 2013). Once developed, such integrated models would allow us to quantify climate-dependent speciation and extinction rates, as well as the strength of dispersal limitation and constraints on niche evolution, which allow such rate differences to translate into spatial patterns of biodiversity. Such complex models will require large amounts of data to be successfully parameterized, including phylogenetic data, current and past occurrences, current and past trait data, 
and current and past environments. Continuing ongoing efforts to assemble and integrate large multi-species datasets is thus pivotal.

\section{ACKNOWLEDGMENTS}

We acknowledge funding from the European Research Council (ERC-2012-StG-310886-

HISTFUNC) and the Danish Council for Independent Research | Natural Science (grant 12125079). 


\section{LITERATURE CITED}

Ackerly D. 2003. Community assembly, niche conservatism, and adaptive evolution in changing environments. Int. J. Plant Sci. 164(3 Suppl.): S165-S84

Ackerly DD, Loarie SR, Cornwell WK, Weiss SB, Hamilton H, et al. 2010. The geography of climate change: implications for conservation biogeography. Divers. Distrib. 16: 476-87

Araújo MB, Nogués-Bravo D, Diniz-Filho JAF, Haywood AM, Valdes PJ, Rahbek C. 2008. Quaternary climate changes explain diversity among reptiles and amphibians. Ecography 31: $8-15$

Azzaroli A, De Giuli C, Ficcarelli G, Torre D. 1988. Late Pliocene to early mid-Pleistocene mammals in Eurasia: Faunal succession and dispersal events. Palaeogeogr. Palaeoclimatol. Palaeoecol. 66: 77-100

Banin L, Lewis SL, Lopez-Gonzalez G, Baker TR, Quesada CA, et al. 2014. Tropical forest wood production: a cross-continental comparison. J. Ecol. 102: 1025-37

Baselga A. 2008. Determinants of species richness, endemism and turnover in European longhorn beetles. Ecography 31: 263-71

Baselga A, Gómez-Rodríguez C, Lobo JM. 2012a. Historical legacies in world amphibian diversity revealed by the turnover and nestedness components of beta diversity. PLoS One 7: e32341

Baselga A, Lobo JM, Svenning J-C, Aragón P, Araújo MB. 2012b. Dispersal ability modulates the strength of the latitudinal richness gradient in European beetles. Glob. Ecol. Biogeogr. 21: $1106-13$

Bertrand R, Lenoir J, Piedallu C, Riofrio-Dillon G, de Ruffray P, et al. 2011. Changes in plant community composition lag behind climate warming in lowland forests. Nature 479: 517-20

Bhagwat SA, Willis KJ. 2008. Species persistence in northerly glacial refugia of Europe: a matter of chance or biogeographical traits? J. Biogeogr. 35: 464-82 
Blach-Overgaard A, Kissling WD, Dransfield J, Balslev H, Svenning J-C. 2013. Multimillion-year climatic effects on palm species diversity in Africa. Ecology 94: 2426-35

Bowen GJ, Clyde WC, Koch PL, Ting S, Alroy J, et al. 2002. Mammalian dispersal at the Paleocene/Eocene boundary. Science 295: 2062-65

Bowersox JR. 2005. Reassessment of extinction patterns of Pliocene molluscs from California and environmental forcing of extinction in the San Joaquin Basin. Palaeogeogr. Palaeoclimatol. Palaeoecol. 221: 55-82

Caccianiga M, Payette S. 2006. Recent advance of white spruce (Picea glauca) in the coastal tundra of the eastern shore of Hudson Bay (Quebec, Canada). J. Biogeogr. 33: 2120-35

Campbell ID, McAndrews JH. 1993. Forest disequilibrium caused by rapid Little Ice Age cooling. Nature 366: 336-38

Carnaval AC, Hickerson MJ, Haddad CFB, Rodrigues MT, Moritz C. 2009. Stability predicts genetic diversity in the Brazilian Atlantic Forest hotspot. Science 323: 785-89

Chapin FS, Starfield AM. 1997. Time lags and novel ecosystems in response to transient climate change in Arctic Alaska. Clim. Change 35: 449-61

Condamine FL, Rolland J, Morlon H. 2013. Macroevolutionary perspectives to environmental change. Ecol. Lett. 16: 72-85

Costion CM, Edwards W, Ford AJ, Metcalfe DJ, Cross HB, et al. 2015. Using phylogenetic diversity to identify ancient rain forest refugia and diversification zones in a biodiversity hotspot. Divers. Distrib. 21: 279-89

Couvreur TLP, Kissling WD, Condamine FL, Svenning J-C, Rowe NP, Baker WJ. 2015. Global diversification of a tropical plant growth form: environmental correlates and historical contingencies in climbing palms. Front. Genet. 5:452 
Crisp M, Cook L, Steane D. 2004. Radiation of the Australian flora: what can comparisons of molecular phylogenies across multiple taxa tell us about the evolution of diversity in present-day communities? Philos. Trans. Roy. Soc. Lond. ser. B 359: 1551-71

Crisp MD, Cook LG. 2011. Cenozoic extinctions account for the low diversity of extant gymnosperms compared with angiosperms. New Phytologist 192: 997-1009

Davis MB. 1986. Climatic instability, time lags, and community disequilibrium In Community ecology, ed. J Diamond, TJ Case, pp. 269-84. New York: Harper \& Row

de Vernal A, Hillaire-Marcel C. 2008. Natural variability of Greenland climate, vegetation, and ice volume during the past million years. Science 320: 1622-25

Dobrovolski R, Melo AS, Cassemiro FAS, Diniz-Filho JAF. 2012. Climatic history and dispersal ability explain the relative importance of turnover and nestedness components of beta diversity. Glob. Ecol. Biogeogr. 21: 191-97

Donoghue MJ, Smith SA. 2004. Patterns in the assembly of temperate forests around the Northern Hemisphere. Philos. Trans. Roy. Soc. Lond. ser. B 359: 1633-44

Dullinger S, Gattringer A, Thuiller W, Moser D, Zimmermann NE, et al. 2012a. Extinction debt of high-mountain plants under twenty-first-century climate change. Nature Clim. Change 2: $619-22$

Dullinger S, Willner W, Plutzar C, Englisch T, Schratt-Ehrendorfer L, et al. 2012b. Post-glacial migration lag restricts range filling of plants in the European Alps. Glob. Ecol. Biogeogr. 21: $829-40$

Dynesius M, Jansson R. 2000. Evolutionary consequences of changes in species' geographical distributions driven by Milankovitch climate oscillations. Proc. Natl. Acad. Sci. USA 97: $9115-20$ 
Eiserhardt WL, Borchsenius F, Plum CM, Ordonez A, Svenning J-C. 2015. Climate-driven extinctions shape the phylogenetic structure of temperate tree floras. Ecol. Lett. 18:263-272

Eriksson O. 1996. Regional dynamics of plants: a review of evidence for remnant, source-sink and metapopulations. Oikos 77: 248-58

Ewald J. 2003. The calcareous riddle: why are there so many calciphilous species in the Central European flora? Folia Geobot. 38: 357-66

Feng G, Mi X, Eiserhardt WL, Jin G, Sang W, et al. 2015. Assembly of forest communities across East Asia - insights from phylogenetic community structure and species pool scaling. Sci. Rep. 5

Feng G, Mi XC, Bøcher PK, Mao LF, Sandel B, et al. 2014. Relative roles of local disturbance, current climate and paleoclimate in determining phylogenetic and functional diversity in Chinese forests. Biogeosciences 11: 1361-70

Fine PVA, Ree RH. 2006. Evidence for a time-integrated species-area effect on the latitudinal gradient in tree diversity. Am. Nat. 168: 796-804

Fitzpatrick MC, Sanders NJ, Normand S, Svenning J-C, Ferrier S, et al. 2013. Environmental and historical imprints on beta diversity: insights from variation in rates of species turnover along gradients. Proc. Roy. Soc. B: Biol. Sci. 280: 20131201

Flynn DFB, Mirotchnick N, Jain M, Palmer MI, Naeem S. 2011. Functional and phylogenetic diversity as predictors of biodiversity-ecosystem-function relationships. Ecology 92: 157381

Fløjgaard C, Normand S, Skov F, Svenning J-C. 2010. Deconstructing the mammal species richness pattern in Europe - towards an understanding of the relative importance of climate, biogeographic history, habitat heterogeneity and humans. Glob. Ecol. Biogeogr. 20: 218-30 
Follieri M, Magri D, Sadori L. 1986. Late Pleistocene Zelkova extinction in central Italy. New Phytol. 103: 269-73

Frelich LE, Hale CM, Scheu S, Holdsworth AR, Heneghan L, et al. 2006. Earthworm invasion into previously earthworm-free temperate and boreal forests. Biol. Invasions V8: 1235-45

Fritz SA, Schnitzler J, Eronen JT, Hof C, Böhning-Gaese K, Graham CH. 2013. Diversity in time and space: wanted dead and alive. Trends Ecol. Evol. 28: 509-16

Gavin DG. 2009. The coastal-disjunct mesic flora in the inland Pacific Northwest of USA and Canada: refugia, dispersal and disequilibrium. Divers. Distrib. 15: 972-82

Graham CH, Moritz C, Williams SE. 2006. Habitat history improves prediction of biodiversity in rainforest fauna. Proc. Natl. Acad. Sci. USA 103: 632-36

Haffer J. 1969. Speciation in Amazonian forest birds. Science 165: 131-37

Hastings A. 2004. Transients: the key to long-term ecological understanding? Trends Ecol. Evol. 19: $39-45$

Hawkins BA, Rueda M, Rangel TF, Field R, Diniz-Filho JAF. 2014. Community phylogenetics at the biogeographical scale: cold tolerance, niche conservatism and the structure of North American forests. J. Biogeogr. 41: 23-38

Herrero C, García-Olivares A, Pelegrí JL. 2014. Impact of anthropogenic $\mathrm{CO}_{2}$ on the next glacial cycle. Clim. Change 122: 283-98

Hewitt G. 2000. The genetic legacy of the Quaternary ice ages. Nature 405: 907-13

Hill RS. 2004. Origins of the southeastern Australian vegetation. Philos. Trans. Roy. Soc. Lond. ser. B 359: $1537-49$

Hinojosa LF, Pérez F, Gaxiola A, Sandoval I. 2011. Historical and phylogenetic constraints on the incidence of entire leaf margins: insights from a new South American model. Glob. Ecol. Biogeogr. 20: 380-90 
Hoffmann MH. 2012. Not across the North Pole: Plant migration in the Arctic. New Phytol. 193: $474-80$

Hooper DU, Chapin FS, Ewel JJ, Hector A, Inchausti P, et al. 2005. Effects of biodiversity on ecosystem functioning: A consensus of current knowledge. Ecol. Monogr. 75: 3-35

Hoorn C, Wesselingh FP, ter Steege H, Bermudez MA, Mora A, et al. 2010. Amazonia through time: Andean uplift, climate change, landscape evolution, and biodiversity. Science 330: $927-31$

Hortal J, Diniz-Filho JA, Bini LM, Rodríguez MÁ, Baselga A, et al. 2011. Ice age climate, evolutionary constraints and diversity patterns of European dung beetles. Ecol. Lett. 14: $741-48$

Hu Q-H, Sun L-G, Xie Z-Q, Emslie SD, Liu X-D. 2013. Increase in penguin populations during the Little Ice Age in the Ross Sea, Antarctica. Scientific Reports 3

Hubbell SP. 2001. The unified neutral theory of biodiversity and biogeography. Princeton: Princeton University Press.

Huntley B, Allen JRM, Collingham YC, Hickler T, Lister AM, et al. 2013. Millennial climatic fluctuations are key to the structure of last glacial ecosystems. PLoS One 8: e61963

Huntley B, Webb III T. 1989. Migration: species' response to climatic variations caused by changes in the Earth's orbit. J. Biogeogr. 16: 5-19

Hutchinson AH. 1918. Limiting factors in relation to specific ranges of tolerance of forest trees. Bot. Gaz. 66: 465-93

Jackson ST, Weng C. 1999. Late Quaternary extinction of a tree species in eastern North America. Proc. Natl. Acad. Sci. USA 96: 13847-52

Jansson R. 2003. Global patterns in endemism explained by past climatic change. Proc. Roy. Soc. B: Biol. Sci. 270: 583-90 
Jansson R, Dynesius M. 2002. The fate of clades in a world of recurrent climatic change: Milankovitch oscillations and evolution. Annu. Rev. Ecol. Systematics 33: 741-77

Jetz W, Fine PVA. 2012. Global gradients in vertebrate diversity predicted by historical areaproductivity dynamics and contemporary environment. PLoS Biol 10: e1001292

Johnstone JF, Chapin FS. 2003. Non-equilibrium succession dynamics indicate continued northern migration of lodgepole pine. Glob. Change Biol. 9: 1401-09

Kissling WD, Baker WJ, Balslev H, Barfod AS, Borchsenius F, et al. 2012a. Quaternary and preQuaternary historical legacies in the global distribution of a major tropical plant lineage. Glob. Ecol. Biogeogr. 21: 909-21

Kissling WD, Eiserhardt WL, Baker WJ, Borchsenius F, Couvreur TLP, et al. 2012b. Cenozoic imprints on the phylogenetic structure of palm species assemblages worldwide. Proc. Natl. Acad. Sci. USA 109: 7379-84

Laliberté E, Zemunik G, Turner BL. 2014. Environmental filtering explains variation in plant diversity along resource gradients. Science 345: 1602-05

LaMarche VC. 1973. Holocene climatic variations inferred from treeline fluctuations in the White Mountains, California. Quat. Res. 3: 632-60

Lavorel S, Garnier E. 2002. Predicting changes in community composition and ecosystem functioning from plant traits: revisiting the Holy Grail. Funct. Ecol. 16: 545-56 Lawing AM, Matzke NJ. 2014. Conservation paleobiology needs phylogenetic methods. Ecography 37: $1109-22$

Lenoir J, Gégout J-C, Guisan A-, Vittoz P-, Wohlgemuth T-, et al. 2010. Cross-scale analysis of the region effect on vascular plant species diversity in southern and northern European mountain ranges. PLoS One 5: e15734 
Leprieur F, Tedesco PA, Hugueny B, Beauchard O, Dürr HH, et al. 2011. Partitioning global patterns of freshwater fish beta diversity reveals contrasting signatures of past climate changes. Ecol. Lett. 14: 325-34

Lewis AR, Marchant DR, Ashworth AC, Hedenäs L, Hemming SR, et al. 2008. Mid-Miocene cooling and the extinction of tundra in continental Antarctica. Proc. Natl. Acad. Sci. USA 105: $10676-80$

Lister AM. 2004. The impact of Quaternary ice ages on mammalian evolution. Philos. Trans. Roy. Soc. Lond. ser. B 359: 221-41

Lister AM. 2013. The role of behaviour in adaptive morphological evolution of African proboscideans. Nature 500: 331-34

Livermore R, Nankivell A, Eagles G, Morris P. 2005. Paleogene opening of Drake Passage. Earth Planet.y Sci. Lett. 236: 459-70

Loarie SR, Duffy PB, Hamilton H, Asner GP, Field CB, Ackerly DD. 2009. The velocity of climate change. Nature 462: 1052-55

Lobo JM, Castro I, Moreno JC. 2001. Spatial and environmental determinants of vascular plant species richness distribution in the Iberian Peninsula and Balearic Islands. Biol. J. Linn. Soc. 73: $233-53$

Lunt ID, Byrne M, Hellmann JJ, Mitchell NJ, Garnett ST, et al. 2013. Using assisted colonisation to conserve biodiversity and restore ecosystem function under climate change. Biol. Conserv. 157: $172-77$

MacPhail MK, Colhoun EA, Fitzsimons SJ. 1995. Key periods in the evolution of the Cenozoic vegetation and flora in western Tasmania: the Late Pliocene. Aust. J. Bot. 43: 505-26

Maldonado-Coelho M. 2012. Climatic oscillations shape the phylogeographical structure of Atlantic Forest fire-eye antbirds (Aves: Thamnophilidae). Biol. J. Linn. Soc. 105: 900-24 
Manchester SR, Chen Z-D, Lu A-M, Uemura K. 2009. Eastern Asian endemic seed plant genera and their paleogeographic history throughout the Northern Hemisphere. J. Systematics Evol. 47: $1-42$

Mathieu J, Davies TJ. 2014. Glaciation as an historical filter of below-ground biodiversity. $J$. Biogeogr. 41: 1204-14

May MR, Provance MC, Sanders AC, Ellstrand NC, Ross-Ibarra J. 2009. A Pleistocene clone of Palmer's oak persisting in southern California. PLoS One 4: e8346

Mayewski PA, Rohling EE, Stager JC, Karlen W, Maasch KA, et al. 2004. Holocene climate variability. Quat. Res. 62: 243-55

Miller ET, Zanne AE, Ricklefs RE. 2013. Niche conservatism constrains Australian honeyeater assemblages in stressful environments. Ecol. Lett. 16: 1186-94

Mittelbach GG, Schemske DW, Cornell HV, Allen AP, Brown JM, et al. 2007. Evolution and the latitudinal diversity gradient: speciation, extinction and biogeography. Ecol. Lett. 10: 315-31

Morlon H, Potts MD, Plotkin JB. 2010. Inferring the dynamics of diversification: a coalescent approach. PLoS Biol 8: e1000493

Nobis MP, Normand S. 2014. KISSMig - a simple model for R to account for limited migration in analyses of species distributions. Ecography 37: 1282-87

Nogués-Bravo D, Pulido F, Araújo MB, Diniz-Filho JAF, García-Valdés R, et al. 2014. Phenotypic correlates of potential range size and range filling in European trees. Perspect. Plant Ecol. Evol. Systematics 16: 219-27

Normand S, Randin C, Ohlemüller R, Bay C, Høye TT, et al. 2013. A greener Greenland? Climatic potential and long-term constraints on future expansions of trees and shrubs. Philos. Trans. Roy. Soc. ser. B 368: 20120479 
Normand S, Ricklefs RE, Skov F, Bladt J, Tackenberg O, Svenning J-C. 2011. Postglacial migration supplements climate in determining plant species ranges in Europe. Proc. Roy. Soc. B: Biol. Sci. 278: 3644-53

Pacala SW, Canham CD, Saponara J, Silander Jr. JA, Kobe RK, Ribbens E. 1996. Forest models defined by field measurements: estimation, error analysis and dynamics. Ecol. Monogr. 66: $1-43$

Pan AD, Jacobs BF, Dransfield J, Baker WJ. 2006. The fossil history of palms (Arecaceae) in Africa and new records from the Late Oligocene (28-27 Mya) of north-western Ethiopia. Bot. J. Linn. Soc. 151: 69-81

Paun O, Lehnebach C, Johansson JT, Lockhart P, Hörandl E. 2005. Phylogenetic relationships and biogeography of Ranunculus and allied genera (Ranunculaceae) in the Mediterranean region and in the European Alpine System. Taxon 54: 911-30

Payette S. 2007. Contrasted dynamics of nothern Labrador tree lines caused by climate change and migrational lags. Ecology 88: 770-80

Pellissier L, Leprieur F, Parravicini V, Cowman PF, Kulbicki M, et al. 2014. Quaternary coral reef refugia preserved fish diversity. Science 344: 1016-19

Pigott CD. 1991. Tilia cordata Miller. J. Ecol. 79: 1147-207

Postigo Mijarra JM, Morla C, Barrón E, Morales-Molino C, García S. 2010. Patterns of extinction and persistence of Arctotertiary flora in Iberia during the Quaternary. Rev. Palaeobot. Palynol. 162: 416-26

Prentice IC, Bartlein PJ, Webb III T. 1991. Vegetation and climate change in eastern North America since the Last Glacial Maximum. Ecology 72: 2038-56

Qian H, Ricklefs RE. 2007. A latitudinal gradient in large-scale beta diversity for vascular plants in North America. Ecol. Lett. 10: 737-44 
Raffi S, Stanley SM, Marasti R. 1985. Biogeographic patterns and Plio-Pleistocene extinction of Bivalvia in the Mediterranean and Southern North Sea. Paleobiology 11: 368-88

Rakotoarinivo M, Blach-Overgaard A, Baker WJ, Dransfield J, Moat J, Svenning J-C. 2013. Palaeo-precipitation is a major determinant of palm species richness patterns across Madagascar: a tropical biodiversity hotspot. Proc. Roy. Soc. B: Biol. Sci. 280: 20123048

Richardson DM, Williams PA, Hobbs RJ. 1994. Pine invasions in the Southern Hemisphere: determinants of spread and invadability. J. Biogeogr. 21: 511-27

Ricklefs RE, Latham RE. 1999. Global patterns of tree species richness in moist forests: distinguishing ecological influences and historical contingency. Oikos 86: 369-73

Rodríguez J. 2006. Structural continuity and multiple alternative stable States in Middle Pleistocene European mammalian communities. Palaeogeogr. Palaeoclimatol. Palaeoecol. 239: 355-73

Rolland J, Condamine FL, Jiguet F, Morlon H. 2014. Faster speciation and reduced extinction in the tropics contribute to the mammalian latitudinal diversity gradient. PLoS Biol. 12: e1001775 Rosauer DF, Jetz W. 2015. Phylogenetic endemism in terrestrial mammals. Glob. Ecol. Biogeogr. 24: $168-79$

Ruddiman WF. 2014. Earth's climate: past and future. New York: W.H. Freeman and Company Saltré F, Saint-Amant R, Gritti ES, Brewer S, Gaucherel C, et al. 2013. Climate or migration: what limited European beech post-glacial colonization? Glob. Ecol. Biogeogr. 22: 1217-27

Sandel B, Arge L, Dalsgaard B, Davies RG, Gaston KJ, et al. 2011. The influence of Late Quaternary climate-change velocity on species endemism. Science 334: 660-64

Sandom C, Faurby S, Sandel B, Svenning J-C. 2014. Global late Quaternary megafauna extinctions linked to humans, not climate change. Proc. Roy. Soc. B: Biol. Sci. 281: 20133254

Sommer RS, Kalbe J, Ekström J, Benecke N, Liljegren R. 2014. Range dynamics of the reindeer in Europe during the last 25,000 years. J. Biogeogr. 41: 298-306 
Soria-Carrasco V, Castresana J. 2012. Diversification rates and the latitudinal gradient of diversity in mammals. Proc. Roy. Soc. B: Biol. Sci. 279: 4148-55

Stohlgren TJ, Barnett DT, Jarnevich CS, Flather C, Kartesz J. 2008. The myth of plant species saturation. Ecol. Lett. 11: 313-22

Svenning J-C. 2003. Deterministic Plio-Pleistocene extinctions in the European cool-temperate tree flora. Ecol. Lett. 6: 646-53

Svenning J-C, Borchsenius F, Bjorholm S, Balslev H. 2008a. High tropical net diversification drives the New World latitudinal gradient in palm (Arecaceae) species richness. J. Biogeogr. 35: $394-406$

Svenning J-C, Fitzpatrick MC, Normand S, Graham CH, Pearman PB, et al. 2010. Geography, topography, and history affect realized-to-potential tree species richness patterns in Europe. Ecography 33: 1070-80

Svenning J-C, Gravel D, Holt RD, Schurr FM, Thuiller W, et al. 2014. The influence of interspecific interactions on species range expansion rates. Ecography 37: 1198-209

Svenning J-C, Normand S, Skov F. 2008b. Postglacial dispersal limitation of widespread forest plant species in nemoral Europe. Ecography 31: 316-26

Svenning J-C, Sandel B. 2013. Disequilibrium vegetation dynamics under future climate change. Am. J. Bot. 100: 1266-86

Svenning J-C, Skov F. 2004. Limited filling of the potential range in European tree species. Ecol. Lett. 7: 565-73

Svenning J-C, Skov F. 2007. Ice age legacies in the geographical distribution of tree species richness in Europe. Glob. Ecol. Biogeogr. 16: 234-45

Szava-Kovats RC, Ronk A, Pärtel M. 2013. Pattern without bias: local-regional richness relationship revisited. Ecology 94: 1986-92 
Tedesco PA, Leprieur F, Hugueny B, Brosse S, Dürr HH, et al. 2012. Patterns and processes of global riverine fish endemism. Glob. Ecol. Biogeogr. 21: 977-87

Terry RC, Li C, Hadly EA. 2011. Predicting small-mammal responses to climatic warming: autecology, geographic range, and the Holocene fossil record. Glob. Change Biol. 17: 301934

Thuiller W, Lavergne S, Roquet C, Boulangeat I, Lafourcade B, Araujo MB. 2011. Consequences of climate change on the tree of life in Europe. Nature 470: 531-34

Thuiller W, Pironon S, Psomas A, Barbet-Massin M, Jiguet F, et al. 2014. The European functional tree of bird life in the face of global change. Nature Commun. 5: 3118

Wanner H, Beer J, Bütikofer J, Crowley TJ, Cubasch U, et al. 2008. Mid- to Late Holocene climate change: an overview. Quat. Sci. Rev. 27: 1791-828

Watrin J, Lézine A-M, Hély C. 2008. Plant migration and plant communities at the time of the "green Sahara". C. R. Geosci. 341: 656-70

Wiens JJ, Donoghue MJ. 2004. Historical biogeography, ecology and species richness. Trends Ecol. Evol. 19: 639-44

Wilf P, Cúneo NR, Johnson KR, Hicks JF, Wing SL, Obradovich JD. 2003. High plant diversity in Eocene South America: evidence from Patagonia. Science 300: 122-25

Willis CG, Ruhfel B, Primack RB, Miller-Rushing AJ, Davis CC. 2008. Phylogenetic patterns of species loss in Thoreau's woods are driven by climate change. Proc. Natl. Acad. Sci. USA 105: $17029-33$

Willis KJ, Kleczkowski A, Crowhurst SJ. 1999. 124,000-year peridicity in terrestrial vegetation change during the late Pliocene epoch. Nature 397: 685-88

Willner W, Di Pietro R, Bergmeier E. 2009. Phytogeographical evidence for post-glacial dispersal limitation of European beech forest species. Ecography 32: 1011-18 
Wisz MS, Broennimann O, Gronkjaer P, Moller PR, Olsen SM, et al. 2015. Arctic warming will promote Atlantic-Pacific fish interchange. Nature Clim. Change 5: 261-65

Woodard SC, Rosenthal Y, Miller KG, Wright JD, Chiu BK, Lawrence KT. 2014. Antarctic role in Northern Hemisphere glaciation. Science 346: 847-51

Wright IJ, Reich PB, Cornelissen JHC, Falster DS, Groom PK, et al. 2005. Modulation of leaf economic traits and trait relationships by climate. Glob. Ecol. Biogeogr. 14: 411-21 


\section{FIGURE CAPTIONS}

\section{Figure 1}

Hypothetical examples of paleoclimatic legacies in biodiversity. A) A climatic event (red) has a transient effect in the outcome of an equilibrium process. In the background climate (grey), the hypothetical property (e.g., species richness, range filling) fluctuates around an equilibrium state (dashed line), but the climatic event (red) causes a departure from the equilibrium (e.g., through mass extinction, range contraction). This leads to a legacy that is only visible during the relaxation phase, i.e., until the property has reached equilibrium again. B) A climatic event (red) has a permanent effect on the outcome of a cumulative process. In the background climate (grey), the growth of the hypothetical property is positive, but during a short climatic event (red) it is strongly negative. After the event, the property is lower at any point in time than if the event had not occurred (stippled line), i.e., the legacy is permanent. C) A permanent change in climate (from blue to red) has a transient effect on an equilibrium process by shifting the equilibrium state (dashed line). If the equilibrium state changes more quickly than the property of interest, a transient legacy will be visible during relaxation to the new equilibrium. D) A permanent change in climate has a permanent effect on a cumulative process. Due to slower growth of the hypothetical property in blue climate, its value is permanently lower than if contemporary (orange) climate had prevailed throughout history.

\section{Figure 2}

Sources and likely durations of time lags in historical legacies in biodiversity and ecosystems. Over very long time scales, such as the 66 million duration of the Cenozoic, the slow development of cumulative processes such as diversification may be important. On time scales of 100,000 to a few 
million years (such as during the Quaternary or across the late Cenozoic), slow adaptation and range shifts may dominate. Over decades to thousands of years (within the Holocene), these factors are likely to remain important, with local population dynamics playing an increasingly important role. Finally, over seconds to years, physiological processes may show important lags.

\section{Figure 3}

Two hypothetical scenarios of paleoclimatic effects on phylogenetic diversity. In A), two clades diversify in separate regions with different climate histories. In this example, diversification rates depend on climate. As low-diversification climate prevailed throughout most of the history of Region 1 , the clade in this region has not only lower species richness, but also lower phylogenetic diversity than expected given the number of species ('phylogenetic clustering'). In B), species of the same clade are subjected to different climates in different regions. In this example, an extreme climate event (e.g., glaciation) acts as an extinction filter. If the traits that determine the ability of species to tolerate glaciation (or recolonize a region after glaciation) are phylogenetically structured (show phylogenetic signal), the species in the glaciated Region 2 will not only be fewer, but also phylogenetically clustered.

\section{Figure 4}

Potential mechanisms generating paleoclimatic legacies in functional diversity (mean and variability of functional traits). As a result of climatic changes - warm (Time 1) to cold (Time 2) to warm conditions (Time 3) - the trait distributions will change, as some trait values are removed for the pool (black boxes) and others evolve in response to new climatic conditions (transparent boxes). 
New trait states do not emerge as soon as climatic conditions change (dashed distributions), but take time to adapt to these new conditions (evolutionary lags; end period in time 2 and 3, solid distributions). As warm conditions return (Time 3), the trait distribution represents only a fraction of the original trait pool, even after traits start responding via evolution, reflecting the legacy of past extinction and evolutionary lags.

\section{Figure 5}

Paleoclimatic filtering on response trait may impose historical legacies in species and functional diversity via cumulative evolutionary effects, extinction, or dispersal-linked filtering during recolonization. These changes may translate in to changes in ecosystem function if the effect trait composition is affected, via interdependencies between response and effect traits. 
with equilibrium

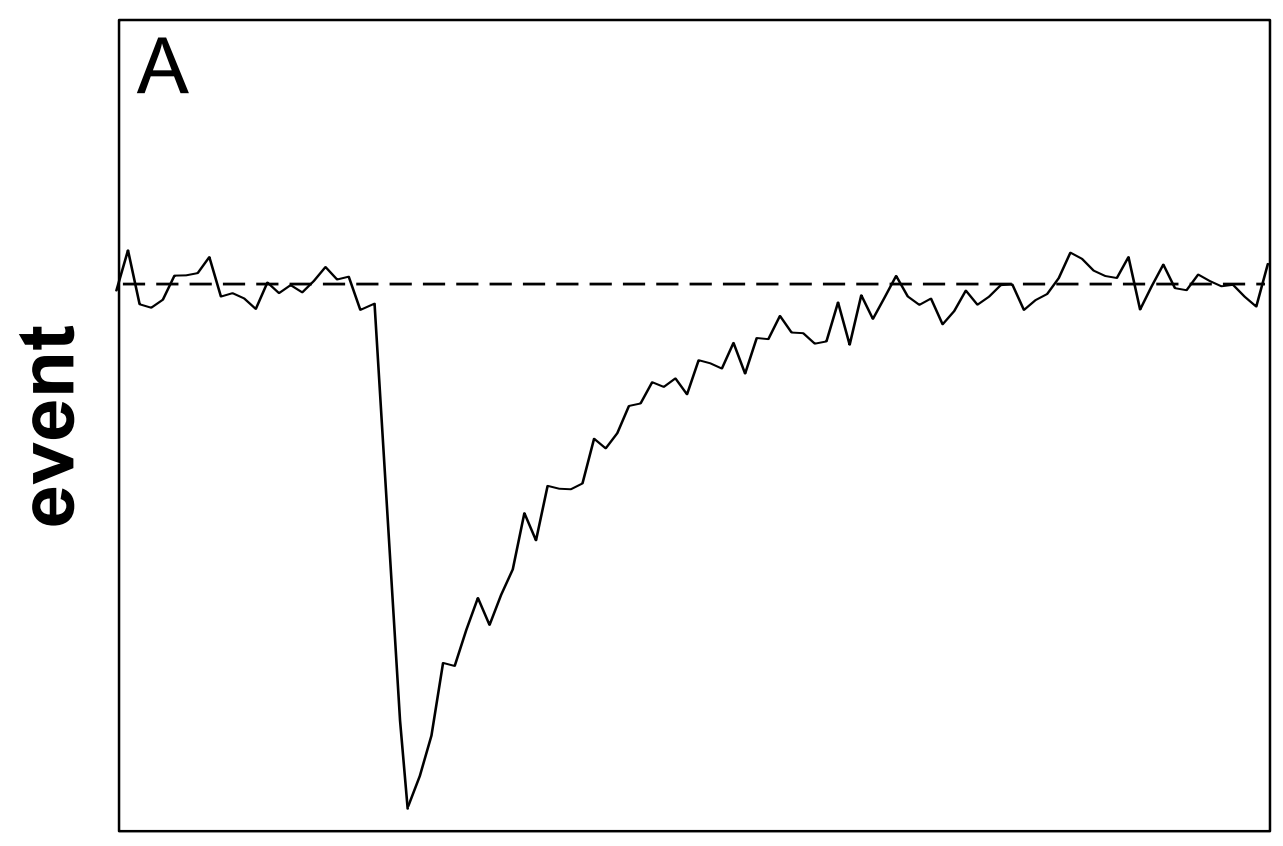

climate: legacy:

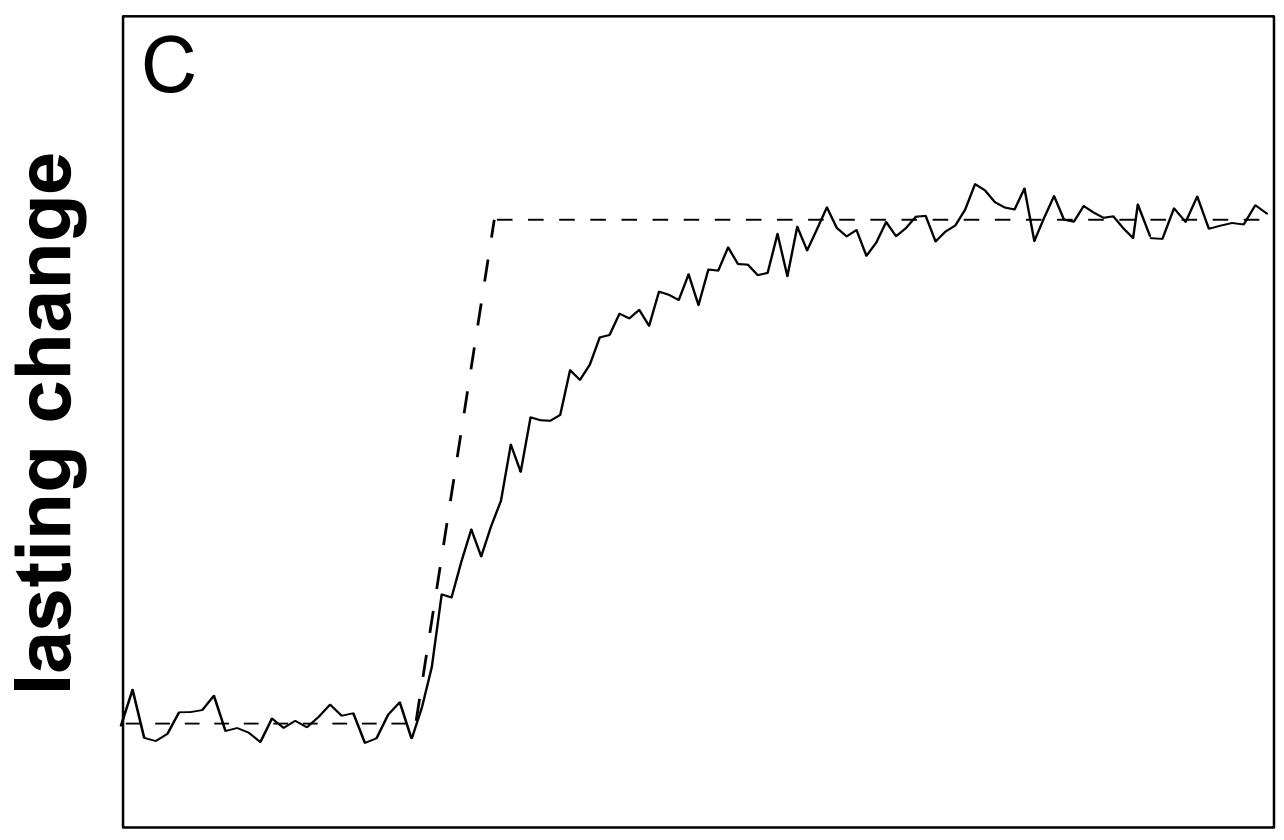

without equilibrium

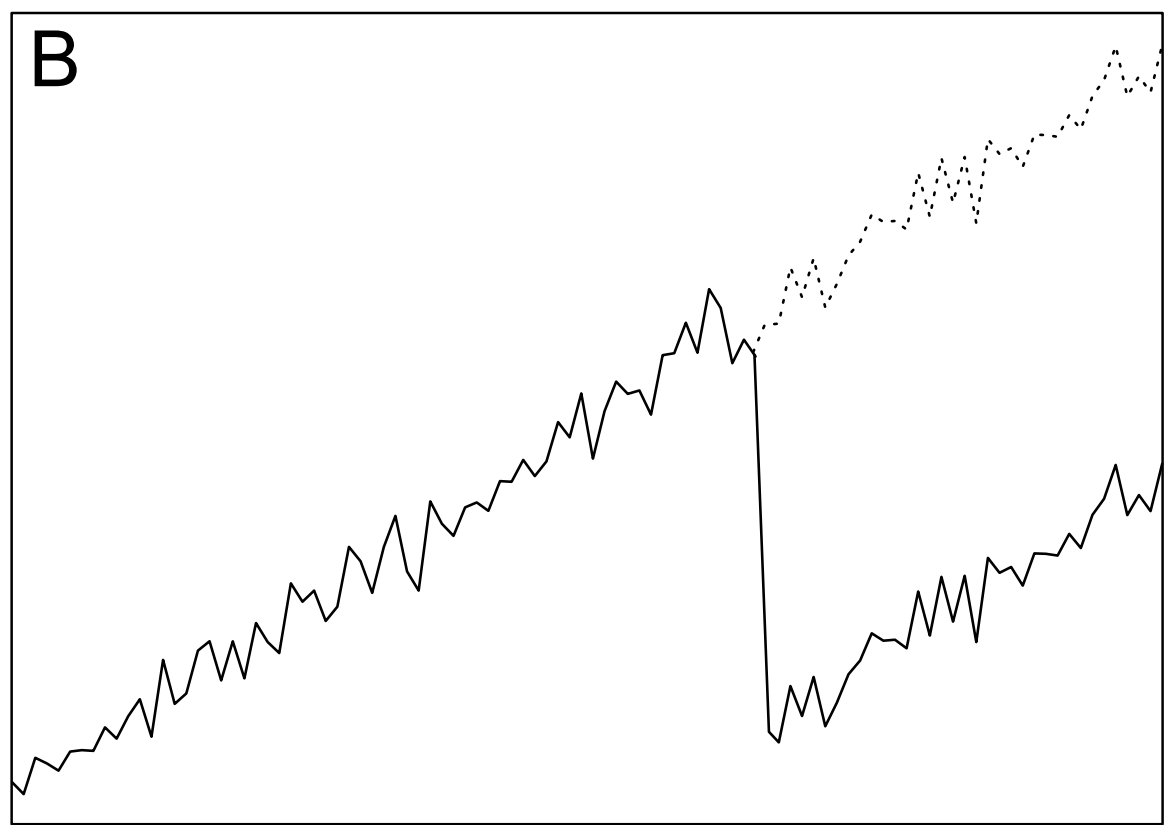

D

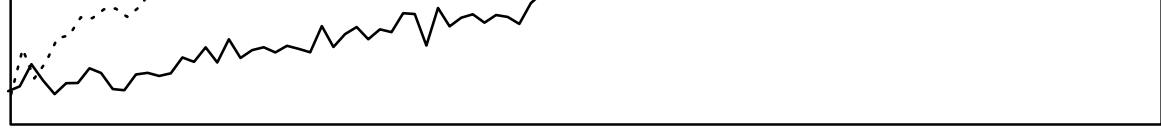

climate:

legacy: 


\section{Years}

Diversification

Lineage adaptation

Range shifts

Population buildup

Physiological responses

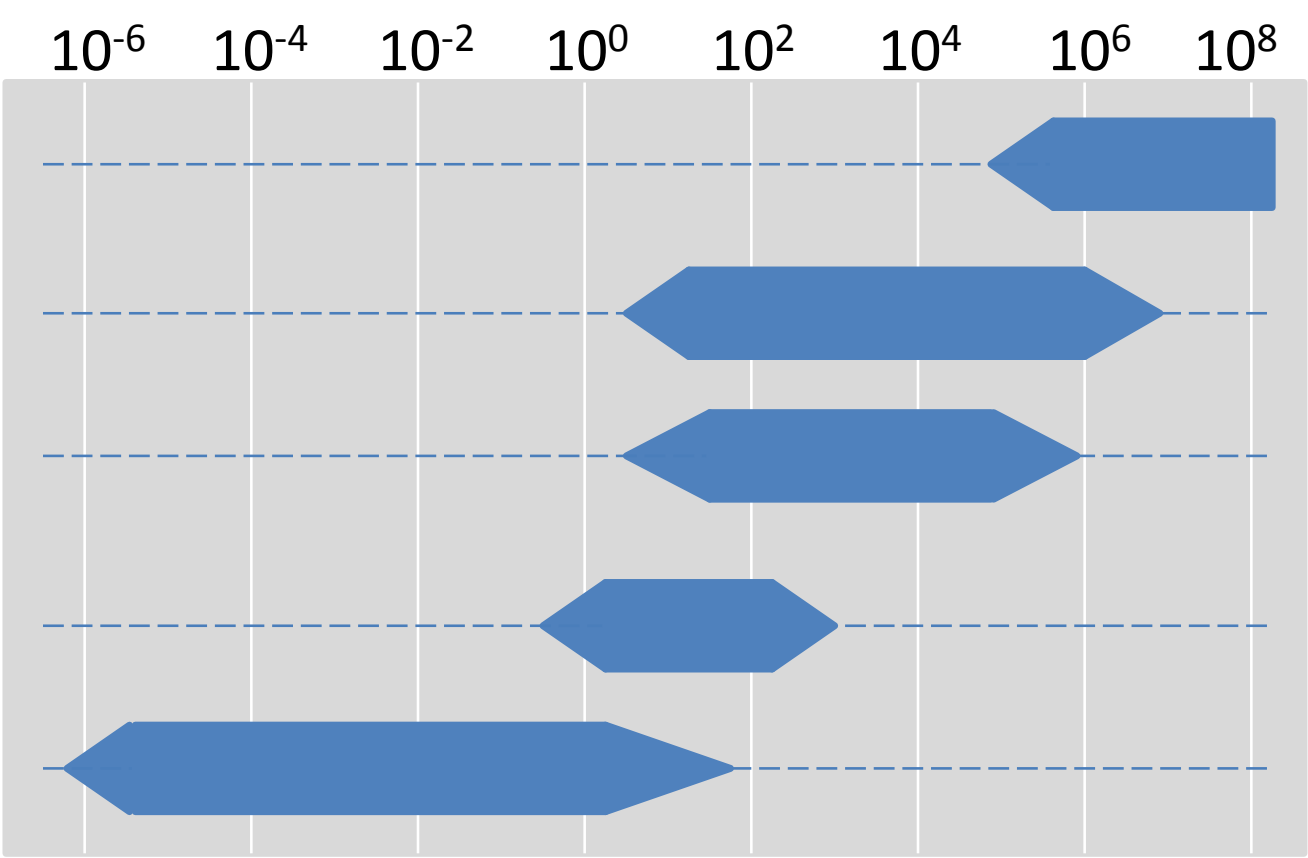




\section{A}

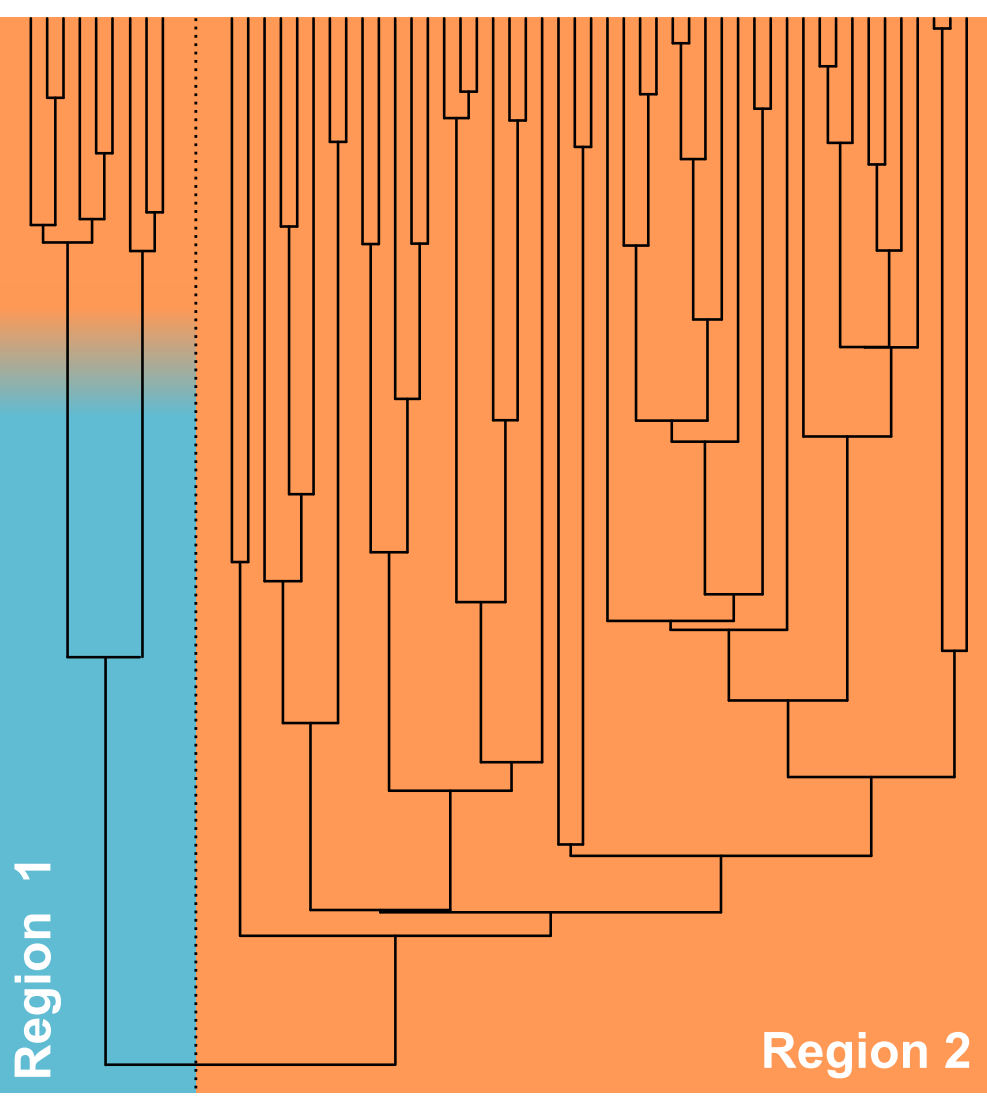

Region 1: unglaciated

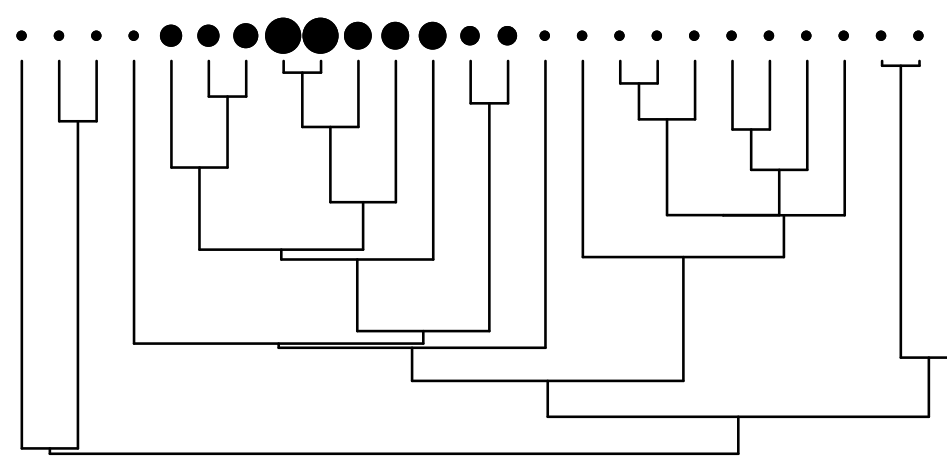

Region 2: glaciated

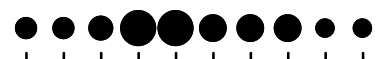

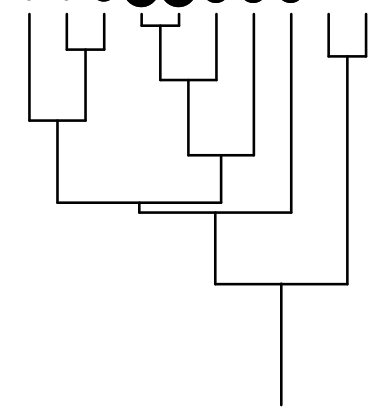

low diversification climate

high diversification climate ability to tolerate glaciation 
Time 3

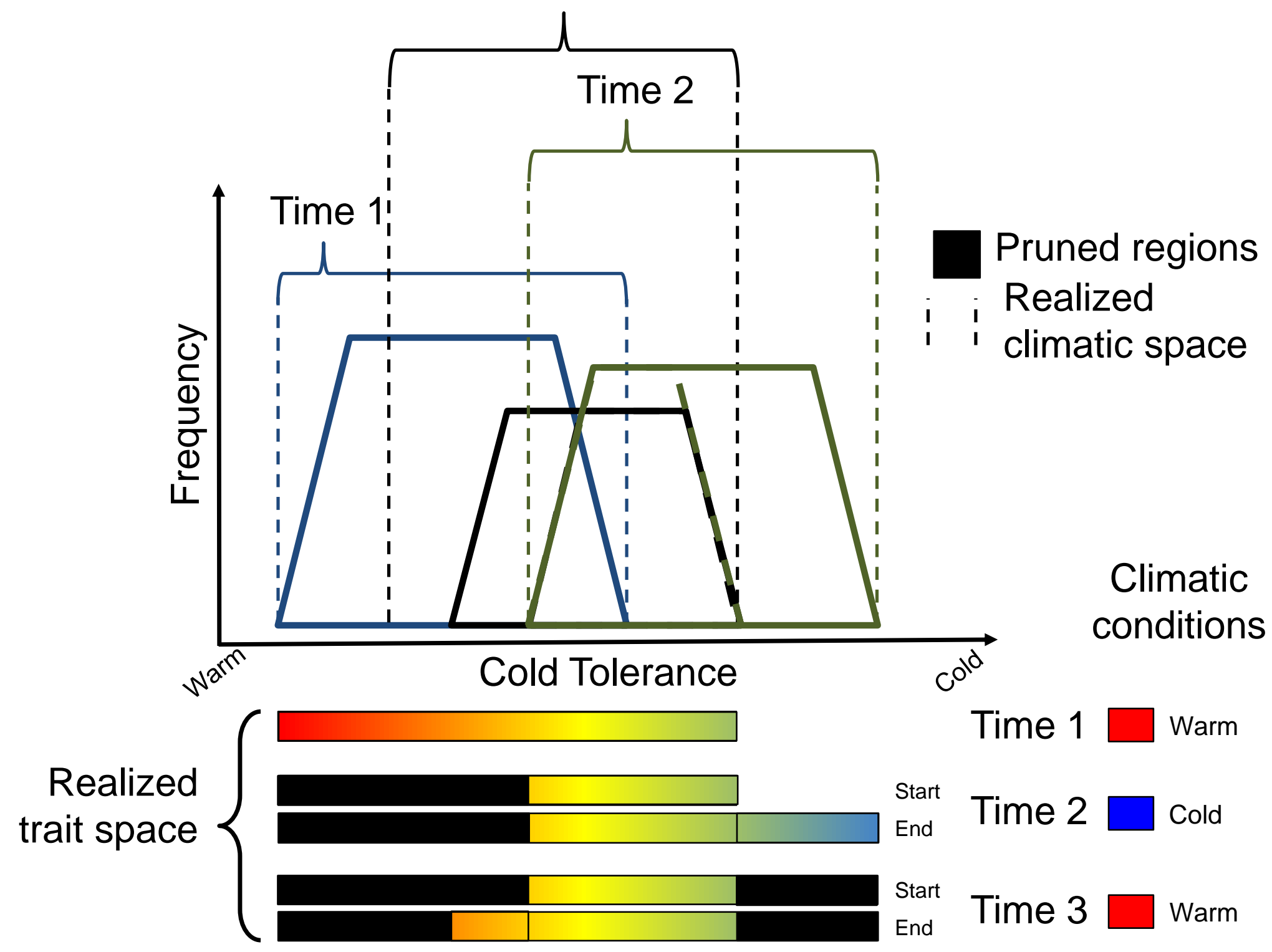




\section{Meta-Community}

and trait structure

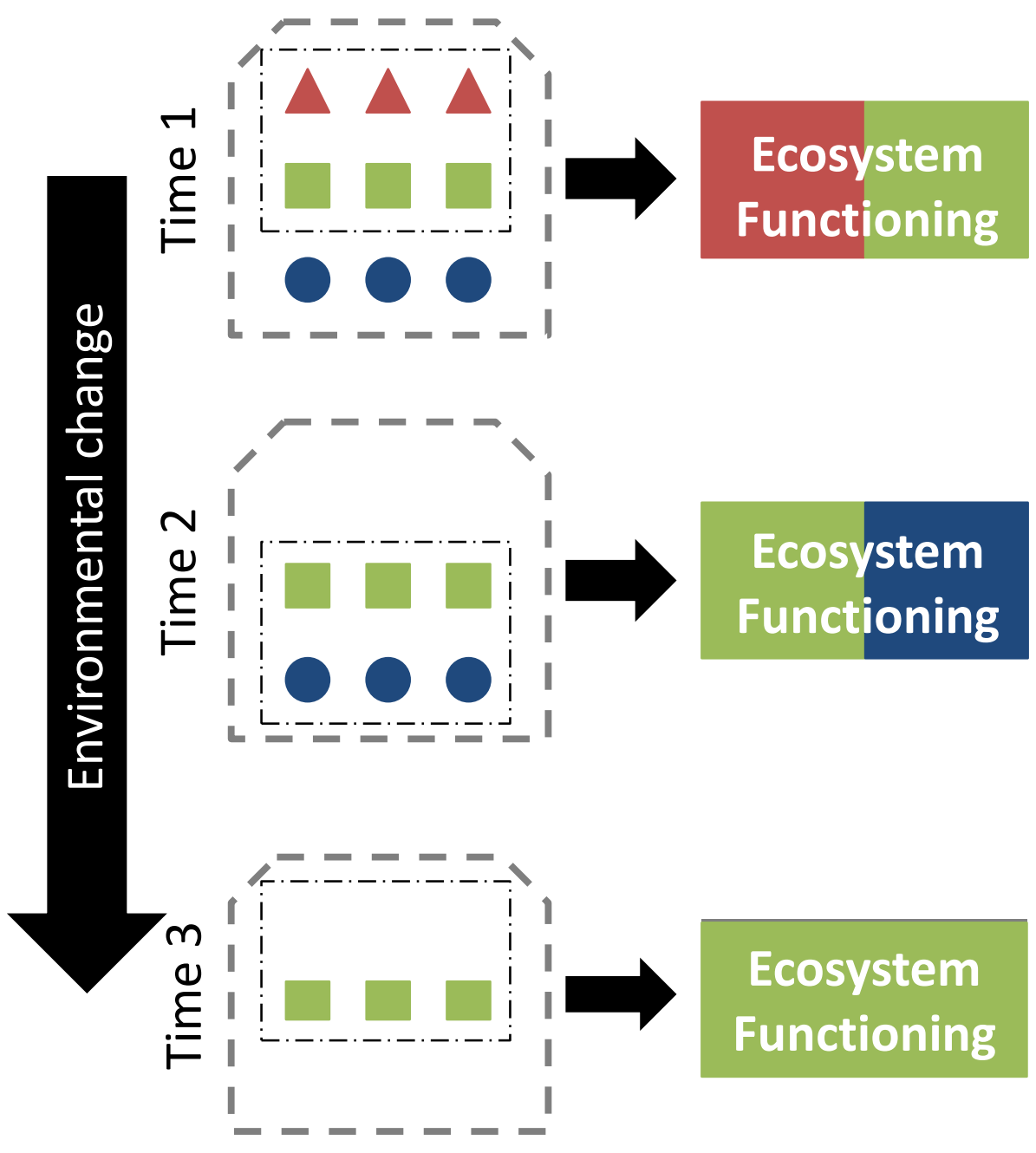

Effect traits

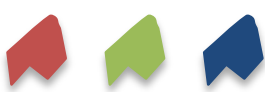

Response traits

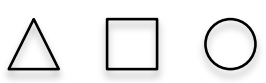

i- Realized

-. Environment al space 